\title{
Research Paper: The Investigation of Sports Injuries in Iranian Handball Premier League
}

\author{
Hashem Piri $^{\text {* }}$ (D), Mohamad Hossein Alizadeh² (D, Khosrow Nasiri
}

1. Department of Sport Injuries and Corrective Exercises, Faculty of Physical Education and Sports Sciences, Allameh Tabataba'i University, Tehran, Iran. 2. Department of Health and Sport Medicine, Faculty of Physical Education and Sport Sciences, University of Tehran, Tehran, Iran.

3. Department of Sport Management, Faculty of Physical Education and Sport Sciences, University of Tehran, Tehran, Iran.

$\begin{gathered}\text { Use yourdevice toscan } \\ \text { and read the article online }\end{gathered}$
Modern Rehabilitation. 2020; 14(1):11-20. http://dx.doi.org/10.32598/JMR.14.1.2
dol http://dx.doi.org/10.32598/JMR.14.1.2

\section{(i) (8)}

Article info:

Received: 11 Jun 2019

Accepted: 12 Oct 2019

Available Online: 01 Jan 2020

\section{Keywords:}

Incidence, Injuries, Handball

\section{A B S T RACT}

Introduction: This study aimed to investigate the mechanism and incidence of sports injuries in male handball players of the Iran premier league.

Materials and Methods: The study data were collected by an injury report form filled out based on the video analysis. A total of 46 out of 90 videos of matches were analyzed. The statistical population of this study consisted 120 players of ten teams. Concerning this point that data were non-parametric, the Chi-squared test $(\mathrm{P}<0.05)$ was used to analyze the gathered data.

Results: Mean \pm SD height, weight, and age of the handball players were $184.3 \pm 6.5 \mathrm{~cm}$, $85.2 \pm 8.5 \mathrm{~kg}, 23.4 \pm 4.2$ years, respectively. A total of 105 injuries were recorded; this rate is equal to 164.5 injuries per $1000 \mathrm{~h}$ of competition. Most injuries occurred in lower extremities $(39.2 \%)$, especially in the knee $(21 \%),\left(\chi^{2}=26.92, \mathrm{P}=0.001\right)$. The injury rate among back players $(54.1 \%)$ was higher compared to other players $\left(\chi^{2}=26.95, \mathrm{P}=0.001\right)$. The difference in the type of contact that resulted in injury was statistically significant $\left(\chi^{2}=60.40, \mathrm{P}=0.001\right)$. The main mechanisms of injury in different playing positions were blocking $(23.8 \%)$, being blocked (21\%), and face hitting with hand $(18.1 \%)\left(\chi^{2}=1.05, \mathrm{P}=0.001\right)$. The rate of injury in the dominant side $(70.4 \%)$ was significantly higher than the non-dominant side $(29.6 \%),\left(\chi^{2}=8.96\right.$, $\mathrm{P}=0.003)$.

Conclusion: Among handball players of the Iranian premier league, most of the injuries occurred in the knee and ankle regions. Back players suffered more injuries in comparison with other players. Also, blocking was the dominant mechanism of injury.

\section{* Corresponding Author:}

Address: Department of Sport Injuries and Corrective Exercises, Faculty of Physical Education and Sports Sciences, Allameh Tabataba’i University, Tehran, Iran. Tel: +98 (919) 9033390

E-mail: hpiri1984@gmail.com 


\section{Introduction}

H

andball is one of the most popular team sports in the world [1]. The International Handball Federation nowadays views 209 national federations among its membership. Like other team sports such as basketball and soccer, injuries are prevalent in handball [24]. A comparative study on injuries of eight team sports at the Athens Olympic showed that handball and football teams had the highest incidence rate of injuries [2].

In conducted research studies in the handball area, different results, regarding the incidence of injury per 1000 $\mathrm{h}$ of competition, have been reported. For example, Langevoort et al. reported that the incidence of injuries in six international handball tournaments was 108 injuries per $1000 \mathrm{~h}$ of player exposure [5]. Using a retrospective questionnaire, Wedderkopp et al. estimated that the incidence of injuries in young female players in European handball was 52 injuries per $1000 \mathrm{~h}$ of competition [6]. Olsen et al. also found that the incidence of injuries in Norwegian handball players was 4.7 per $1000 \mathrm{~h}$ of competition [7].

Initial studies indicate that the incidence of injuries is two-fold in back players, compared with other players [8-11]. Besides, Wedderkopp et al. in a study argued that in Denmark, the maximum incidence of injury happens for line and back players because they have intense collisions during the matches [12]. Many researchers have stated that ankle injury is the most common injury among the different parts of the body [12-18]. While few investigators have considered the knee as the most injured part of the body $[4,6]$. Two studies reported that head is the most injured part of the body $[3,5]$.

Earlier studies on handball players indicate that the mechanism of most injuries is non-contact type, and only a small percentage of injuries occur in contact situations $[11,19]$. However, several studies reported the mechanism of injuries, as the contact type in nature [2, $4,5,12,20]$. One study showed no association between the dominant side and injury in lower extremities [13]. Assessment of sports injuries provides not only essential epidemiological information but also an opportunity to review long-term changes in the frequency and outcomes of injury conditions. Meanwhile, this information can be used to compare the injuries of this sport with other sports. To prevent sports injuries, we need a structured four-phase approach. The first phase of this approach includes the definition of injury in terms of incidence and intensity. In the next phase, factors and mechanisms of injury will be identified. The third phase comprises essential measures to reduce the risk of incidence and severity of injuries in the future. The preventive measures in the third phase should be based on the obtained data from the previous phases. The fourth phase is devoted to evaluating the effectiveness of preventive measures, which will be accomplished by the repetition of the first phase [21].

Despite many handball players and the growth of this sport in Iran, a comprehensive study has not been done yet about the injuries of players and its affecting factors. Therefore, this study was intended to examine the incidence and mechanism of injuries of handball players engaged in the Iran premier league.

\section{Materials and Methods}

This study aims to investigate the injuries of male players in the Iranian handball premier league. Therefore, 46 (out of 90 matches) videos of games, which were available in the Iran Handball Federation and the related clubs, were analyzed. Information was attained through injury record form and video analysis of the available films of matches using injury record forms of Fuller et al., Junge et al., and Hawkins and Fuller [22-24]. The injury record form used for this study was modified and adjusted. The statistical population of the research consisted of the players of ten teams in the Iranian handball premier league. The study sample included those players who were injured at least once during the competitions.

The injuries per $1000 \mathrm{~h}$ of competition, the injured part of the body, playing positions, the type of contact resulting in injury, mechanism of injury (new categorization), and incidence of injury in the dominant and non-dominant sides were investigated. In this study, any event in which players needed the medical team and received treatments during the matches were considered as injury [25]. To measure the incidence of injuries per $1000 \mathrm{~h}$, the total time that players were at risk of injuries (exposure time) was calculated. The number of $h$ that players were at risk was calculated as follows: the number of matches multiplied by the number of players in each match multiplied by the duration of a match (one hour), minus the whole time during which any player was out of the field (2-minute suspensions and disqualifications by a red card). By fitting the exposure time and number of injuries into the following formula, the incidence of injuries per $1000 \mathrm{~h}$ of competition was calculated: 
Incidence of injuries per $1000 h=1000 \times$ number of injuries/the h of exposure

Also, the number of injuries was reported per match. To assess more accurately the incidence of injury in different playing positions, we divided the players into five categories in terms of their duties and playing positions: three back players, one center and two side players, two wing players, one line player, and a goalkeeper. In this study, throwing hand and its ipsilateral leg were intended to be dominant [26].

Concerning the type of contact leading to injury, if the player were injured due to the direct impact of the opponent, the contact would be considered as direct contact. If the player were also injured due to pulling or impacting some area of the body other than the injured area, the contact would be considered as indirect contact. Meanwhile, if the player was injured due to running, pivoting, and landing, the injury was considered as non-contact [7]. In a new categorization, the mechanisms of injury included the following items: landing, plant and cutting, being pushed, blocking, being blocked, running, pivoting, collision with the ball, face hitting with hand, goalpost collision, diving, shooting and others.
Anthropometric data of the players were obtained from the Iran Handball Federation. Anatomic injured areas were categorized as follows: head and neck (head, face, neck, and cervical vertebrate), trunk (sternum or ribs, thoracic vertebrae, lumbar vertebrae, abdomen, and pelvis), lower extremity (hip, thigh, groin, knee, tibia, ankle, foot, and toes), and upper extremities (shoulder, arm, forearm, wrist, hand, and fingers) [27]. After collecting the information, SPSS v. 16 was used for data analysis. Considering nonparametric nature of data, we used the Chi-squared test (significance level of $\mathrm{P}<0.05$ ) to determine whether there is a statistically significant difference in injury incidence at different parts of the body, incidence of injury in different playing positions, type of contacts resulting in injury, mechanism of injury (new categorization), and rate of injury in dominant and non-dominant sides.

\section{Results}

Mean \pm SD of height, weight, and age for handball players were $184.3 \pm 6.5 \mathrm{~cm}, 85.2 \pm 8.5 \mathrm{~kg}, 23.4 \pm 4.2$ years, respectively. In total, 105 injuries were recorded. Considering the number of $\mathrm{h}$ that players were at risk, the estimated total exposure time was $638 \mathrm{~h}$. Also, the

Table 1. Location of injuries by body part

\begin{tabular}{|c|c|}
\hline Locations & No. (\%) \\
\hline Head and face & $38(36)$ \\
\hline Spinal vertebrae & $4(3.8)$ \\
\hline Rib and sternum & $3(2.9)$ \\
\hline Abdomen & $4(3.8)$ \\
\hline Pelvic and hip & $6(5.7)$ \\
\hline Shoulder and humerus & $4(3.8)$ \\
\hline Forearm and elbow & $6(5.7)$ \\
\hline Hand and wrist & $3(2.9)$ \\
\hline knee & $22(21)$ \\
\hline Ankle & $15(14)$ \\
\hline Total & 105 (100) \\
\hline
\end{tabular}

$J \mathrm{MR}$

Table 2. Observed and expected frequencies about the location of injuries

\begin{tabular}{ccc}
\hline Location of Injury & Observed Injuries & Expected Injuries \\
\hline Head and face & 38 & 26.2 \\
Trunk & 13 & 26.2 \\
Upper extremities & 13 & 26.2 \\
Lower extremities & 41 & 26.2 \\
Total & 105 & - \\
\hline
\end{tabular}


Table 3. Observed and expected frequencies about playing position in injured players

\begin{tabular}{ccc}
\hline Playing Position & Observed Injuries & Expected Injuries \\
\hline Goalkeeper & 14 & 21 \\
Back (side) & 41 & 21 \\
\hline Back (center) & 13 & 21 \\
Wing & 23 & 21 \\
Line player & 14 & 21 \\
Total & 105 & - \\
\hline
\end{tabular}

$J M R$

Table 4. Observed and expected frequencies about the type of contact resulted in injury

\begin{tabular}{ccc}
\hline Mechanism & Observed injuries & Expected injuries \\
\hline Non-contact & 22 & 35 \\
Direct contact & 72 & 35 \\
Indirect contact & 11 & 35 \\
Total & 105 & - \\
\hline
\end{tabular}

JMR

incidence of injury per $1000 \mathrm{~h}$ was 164.5 . When the incidence of injury was calculated based on the number of matches, injury incidence was 2.28 injuries per match.

Study results showed a significant difference in injury incidence of different parts of the body $\left(\chi^{2}=26.928\right.$, $\mathrm{P}=0.001$ ) so that the most injuries occurred in the lower extremities (39.2\%), especially knee (21\%) and ankle (14.3\%). Furthermore, after the lower extremities, the highest incidence of injuries occurred at the head and face $(36.2 \%)$ (Table 1,2$)$.

Concerning the incidence of injury in different playing positions, the results showed a significant differ- ence $\left(\chi^{2}=26.952, \mathrm{P}<0.05\right)$ (Table 3$)$. Most injuries were observed in back players $(51.4 \%)$, followed by wing players $(21.9 \%)$. The incidence rate of $13.3 \%$ was observed in line players and goalkeepers. Once the incidence of injury was separately calculated per $1000 \mathrm{~h}$, it was identified that back players had the maximum rate of injury (222 injuries per $1000 \mathrm{~h}$ ), followed by wing players and goalkeepers (152 injuries for each of them). The incidence rate of injury in back players (center) was 144 injuries per $1000 \mathrm{~h}$, and the minimum incidence of injury (125 injuries per $1000 \mathrm{~h}$ ) was observed in wing players (Figure 1).

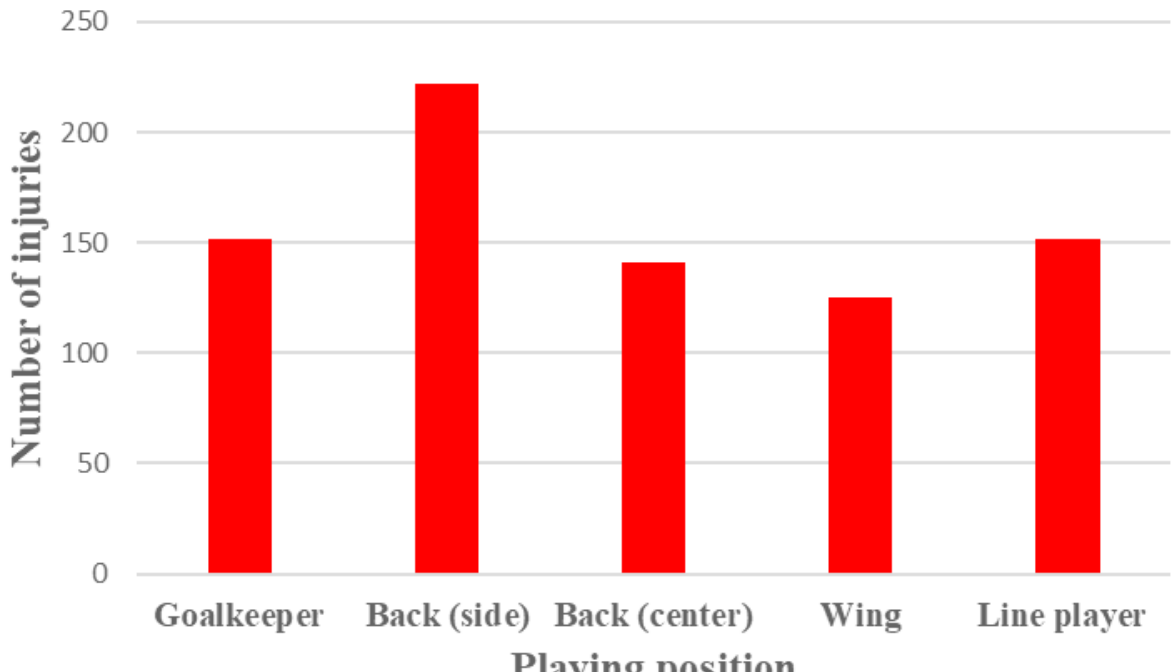

Playing position

Figure 1. Injury incidence in different playing positions per $1000 \mathrm{~h}$ 


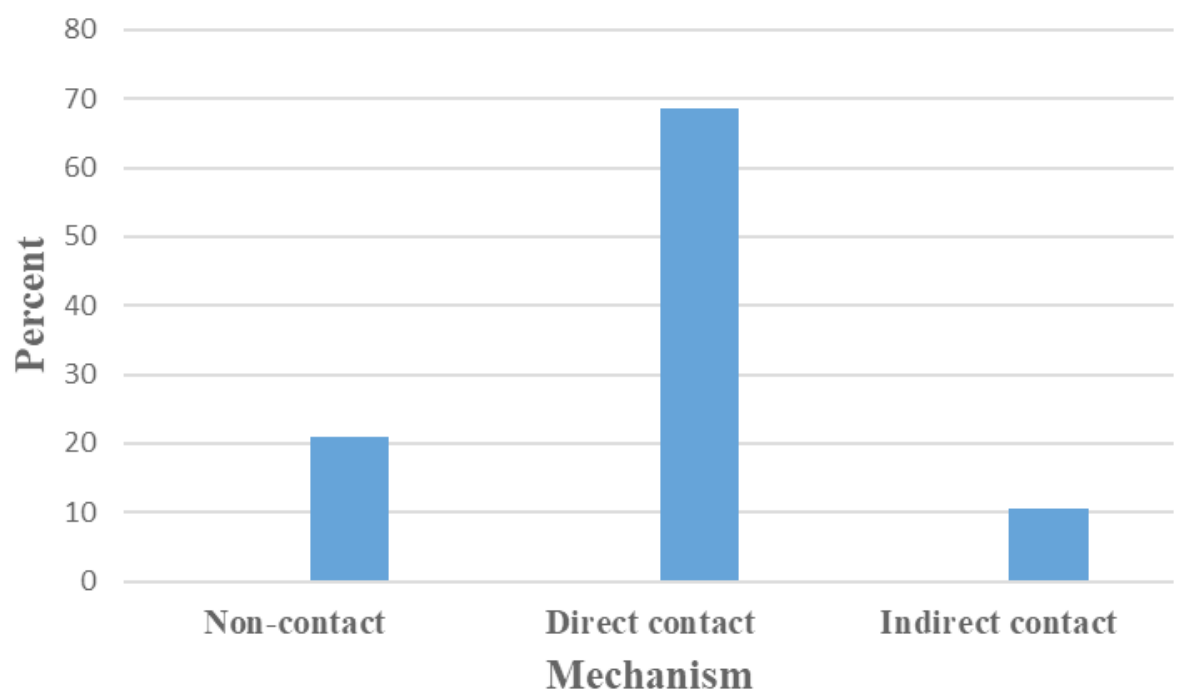

Figure 2. Types of contact that resulted in injury

Concerning the type of contact that resulted in injury in different playing position, the results showed that the injuries of handball players, except for goalkeepers, are more of the contact type. The results showed that back players (center, side) suffered from head and face injuries, while goalkeepers suffered from ankle injuries, and knee injuries were more observed in wing players.

After head and face injuries, knee injuries were the second most common injuries in line players. Considering the incidence of injuries in different phases, the results showed that back and line players were more injured in the attack phase (36 injuries vs 19 injuries). On the other hand, wing players and goalkeepers were more injured in the defense phase (24 injuries versus 13 injuries). According to the results of this research, $79 \%$ of injuries occurred due to contact. Only $21 \%$ of injuries were noncontact by nature (Figure 2). This difference in the type of contacts that resulted in injury was statistically significant $\left(\chi^{2}=60.400, \mathrm{P}<0.05\right)$ (Table 4).

Furthermore, the results of this study indicated that most of the non-contact injuries occurred in the knee and ankle (in total, $61 \%$ of non-contact injuries). The main mechanisms of injuries in different playing positions were being blocked (23.8\%), blocking (21\%), and

Table 5. Observed and expected frequencies of injury mechanisms

\begin{tabular}{|c|c|c|}
\hline Injury Mechanism & Observed Injuries & Expected Injuries \\
\hline Landing & 10 & 8.1 \\
\hline Plant and cutting & 4 & 8.1 \\
\hline Being pushed & 8 & 8.1 \\
\hline Blocking & 22 & 8.1 \\
\hline Being blocked & 25 & 8.1 \\
\hline Running & 1 & 8.1 \\
\hline Pivoting & 4 & 8.1 \\
\hline Collision with ball & 4 & 8.1 \\
\hline Face hitting with hand & 19 & 8.1 \\
\hline Collision with Goalpost & 1 & 8.1 \\
\hline Diving & 3 & 8.1 \\
\hline Shooting & 2 & 8.1 \\
\hline Others & 2 & 8.1 \\
\hline Total & 105 & - \\
\hline
\end{tabular}




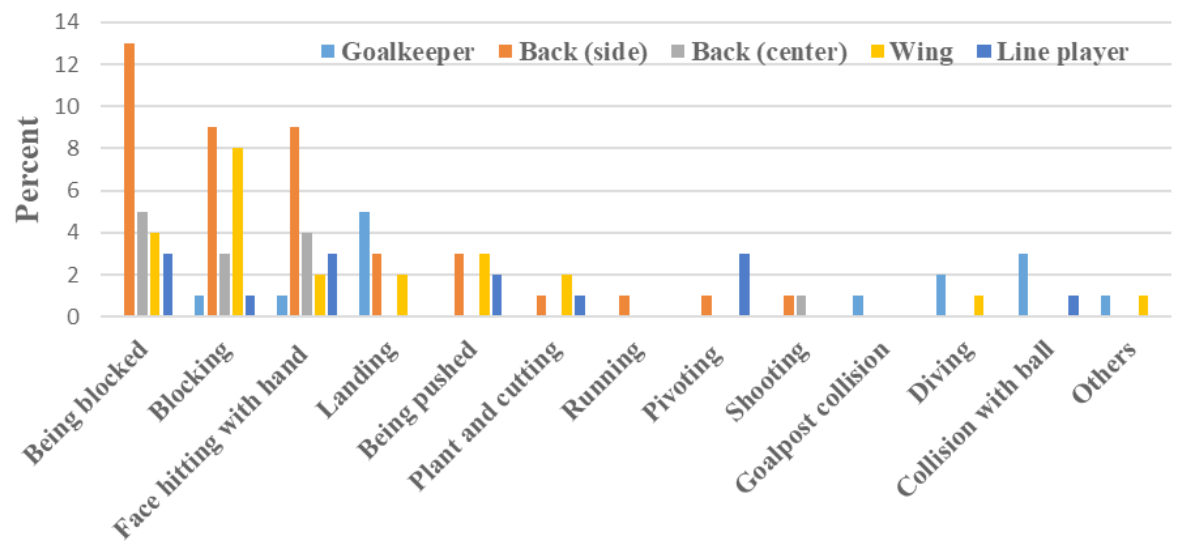

Mechanism

Figure 3. The mechanisms of injuries for different playing position

Table 6. Observed and expected frequencies of the injured side

\begin{tabular}{ccc}
\hline Injured Side & Observed Injuries & Expected Injuries \\
\hline Dominant & 38 & 27 \\
Non-dominant & 16 & 27.0 \\
Total & 54 & - \\
\hline
\end{tabular}

face hitting with hand $(18.1 \%)\left(\chi^{2}=1.05, \mathrm{P}=0.001\right)$ (Table $5)$. The goalkeepers were more injured due to landing and collision with the ball, while the main mechanism of injury in the back players (side and center) was being blocked. Two main injury mechanisms in wing players were blocking and being blocked. Being blocked, pivoting, and face hitting with hand were common mechanisms of injury in line players (Figure 3 ).

Also, the results showed that the incidence of injury in the dominant side $(70.4 \%)$ was significantly higher compared with the non-dominant side $(29.6 \%)\left(\chi^{2}=8.96\right.$, $\mathrm{P}=0.003$ ) (Table 6). The injury incidence of lower extremities in the dominant side $(75.6 \%)$ was higher than the non-dominant side $(24.4 \%)$, while no considerable difference was observed in the upper extremities.

\section{Discussion}

In this research, injury incidence per $1000 \mathrm{~h}$, location of injury in the body, the position of the injured players, type of contact that resulted in injury, injury mechanism, and incidence of injuries in both dominant and non-dominant sides were investigated.

Based on the results, the incidence of injury per 1000 $\mathrm{h}$ was equal to 164.5 injuries. A wide range of injury incidence rates has been reported by scientists, including
Olsen et al. (4.7 injuries per $1000 \mathrm{~h}$ ), Wedderkopp et al. (52 injuries per $1000 \mathrm{~h}$ ), Langevoort et al. (108 injuries per $1000 \mathrm{~h}$ ), Junge et al. (114 injuries per $1000 \mathrm{~h}$ ), and Tsigilis et al. (18.4 injuries per $1000 \mathrm{~h}$ ) [2, 5-7, 28]. It could be said that differences in method, the definition of injury, level of players, and statistical population are the reasons for these considerable differences. For example, Olsen et al., in a study in Norway, reported the injury incidence in both male and female handball players at different levels [7]. Tsigilis et al. used a self-reported questionnaire to investigate injury incidence among Greek male team handball players and defined injury as an incident sustained during practice or competition, which led to a medical situation such as pain, disability, and prohibited participation for at least one day after the date of the event [28].

According to the results of the present study, most injuries occurred in the lower extremities (39.2\%), especially knee (21\%) and ankle (14.3\%) areas. These study results are consistent with previous studies [12, 14, 2933]. Presumably, the high incidence of knee injuries in handball players is due to the rapid changes in the movement direction, high rate of falling, the collision between player's knee, tough surface of the ground, and landing $[24,34,35]$. After the lower extremities, the head and face had the highest risk (36.2\%). Junge et al. reported that $34 \%$ of all handball-related injuries oc- 
curred in the head [2]. The high handball-related injuries in head and face are caused by the contact character of this sport [36]. To decrease the head-related injuries in handball, we recommend applying more serious punishments and regulations.

According to the research results, the maximum incidence of injury occurred in the back players (51.4\%). This finding is consistent with Jorgensen et al., Fagerli et al., Lindblad et al., Strand et al., Wedderkopp et al., Reckling et al., Wedderkopp et al., and Olsen et al. studies [4, 6, 8-11, 17, 37]. Indeed, all mentioned researchers concluded that the back players suffer from the highest incidence of injury.

The higher incidence of injury in back players, compared with other players, might be due to explosive movements, exceptional handball steps, intensive involvements with opponent players, and too rapid changes in direction in back players [37]. Furthermore, Ohnjec et al. reported that back players have the highest rate of throwing compared with other players [38]. Since the throwing action requires the ball possession and the ball possession exposes the ball possessor at the risk of contacts and injuries. Thus this factor can be considered as a cause of a high incidence of injuries in these players. In contrast, Seil et al. believed that wing players face the highest incidence of injuries [13].

Different research methods used in the present study and Seil et al. study can be a possible reason for this difference. Seil et al. used a questionnaire to investigate injury incidence in German handball clubs at the amateur level. In comparison, the video analysis method was used in this study. In this method, it is possible to repeat the leading to injury accidents, and this method provides other abilities, including the exact records of time and place in which injuries have occurred. Furthermore, it provides the exact and reliable description of the injury mechanism.

Concerning the type of contacts leading to injuries, the results of the present research showed that $79 \%$ of injuries were caused by contact. Several studies reported that more than $80 \%$ of injuries could be attributed to contact in international tournaments [2, 20, 39]. Wekesa et al., Olsen OE. et al., Olsen O. et al., and Seil et al. achieved the same results, too $[4,7,13,33]$. The high percentage of contact injuries in handball can be due to handball's rules, which have fewer limitations, compared with other sports. Additionally, it can also be caused by the nature of the handball game. The high percentage of contact injuries in handball players re- quire referees to be more decisive to prevent injuries and also show the importance of fair play to protect players firmly and carefully from injuries.

The results of this study are inconsistent with Myklebust et al., Olsen et al., and Petersen et al. results [16, $19,35]$. This inconsistency could probably be due to this factor that the researchers mentioned above investigated the specific parts of the body. For example, Petersen et al. addressed the mechanism of ankle injuries concerning sprain [16]. We found no study concerning the new categorization of the mechanism of injuries. Therefore, the results of this study cannot be compared to the results of previous studies.

The high percentage of injuries caused by blocking and being blocked can be attributed to the contact character of the handball game. Also, its rules have fewer restrictions for players. The results also showed that the incidence of injury was significantly higher $\left(\chi^{2}=17.886\right.$, $\mathrm{P}>0.05)$ in the dominant side $(70.4 \%)$, compared with the non-dominant side (29.6\%). Seil et al. reported no association between the dominant side and injury in lower extremities in handball players [13]. The causes of this difference are unclear. Since the results of this study indicated that $80 \%$ of handball injuries were due to contact, more contacts occurred on the dominant side would lead to the high incidence of injuries on the dominant side.

In the present study, all events at which players needed to the medical team were considered as injury. As a consequence, the incidence of injury could have been overestimated, i.e., the "exact" incidence of injuries could be even lower than reported. Another limitation of the study is that throwing hand and its ipsilateral leg was considered to be dominant because this is not a rule. In some cases, the dominant leg and hand are not ipsilateral, and the limb dominance phenomenon is task-dependent, the results should be regarded with caution.

\section{Conclusion}

According to the results of this study, injury incidence was relatively high in male handball players in the Iranian premier league. Among different parts of the body, most injuries occurred in the knee and ankle regions. Back players suffered more injuries compared with other players. Also, blocking was the dominant mechanism of injury in handball players in the Iranian premier league. 


\section{Ethical Considerations}

\section{Compliance with ethical guidelines}

The Ethics Committee of Research at University of Tehran, Department of Health and Sports Medicine approved the study.

\section{Funding}

This research did not receive any specific grant from funding agencies in the public, commercial, or not-forprofit sectors.

\section{Authors contributions}

All authors equally contributed to conceptualization, methodology, formal analysis, investigation, resources, data curation, writing the original draft, and project administration.

\section{Conflict of interest}

The authors declared no conflict of interest.

\section{References}

[1] Laver L, Myklebust G. Handball injuries: Epidemiology and injury characterization. In: Doral M, Karlsson J, editors. Sports Injuries: Prevention, Diagnosis, Treatment and Rehabilitation. Berlin/Heidelberg: Springer; 2015. p. 2781-805 [DOI:10.1007/978-3-642-36569-0_287]

[2] Junge A, Langevoort G, Pipe A, Peytavin A, Wong F, Mountjoy $M$, et al. Injuries in team sport tournaments during the 2004 Olympic Games. The American Journal of Sports Medicine. 2006; 34(4):565-76. [DOI:10.1177/0363546505281807] [PMID]

[3] Oehlert K, Drescher W, Petersen W, Zantop T, Gross V, Hassenpflug J. [Injuries in Olympic handball tournaments: A video analysis (German)]. Sportverletzung Sportschaden. 2004; 18(2):80-4. [DOI:10.1055/s-2004-813031] [PMID]

[4] Olsen OE, Myklebust G, Engebretsen L, Bahr R. Injury pattern in youth team handball: A comparison of two prospective registration methods. Scandinavian Journal of Medicine \& Science in Sports. 2006; 16(6):426-32. [DOI:10.1111/j.16000838.2005.00484.x] [PMID]

[5] Langevoort G, Myklebust G, Dvorak J, Junge A. Handball injuries during major international tournaments. Scandinavian Journal of Medicine \& Science in Sports. 2007; 17(4):400-7. [DOI:10.1111/j.1600-0838.2006.00587.x]
[6] Wedderkopp N, Kaltoft M, Holm R, Froberg K. Comparison of two intervention programmes in young female players in European handball-with and without ankle disc. Scandinavian Journal of Medicine \& Science in Sports. 2003; 13(6):371-5. [DOI:10.1046/j.1600-0838.2003.00336.x] [PMID]

[7] Olsen OE, Myklebust G, Engebretsen L, Holme I, Bahr R. Exercises to prevent lower limb injuries in youth sports: Cluster randomised controlled trial. BMJ. 2005; 330(7489):449. [DOI:10.1136/bmj.38330.632801.8F] [PMID] [PMCID]

[8] Fagerli UM, Lereim I, Sahlin Y. [Injuries in handball players (Norwegian)]. Tidsskrift for den Norske Laegeforening Tidsskrift for Praktisk Medicin, ny Raekke. 1990; 110(4):475-8. https://europepmc.org/article/med/2309195

[9] Jørgensen U. Epidemiology of injuries in typical Scandinavian team sports. British Journal of Sports Medicine. 1984; 18(2):59-63. [DOI:10.1136/bjsm.18.2.59] [PMID] [PMCID]

[10] Lindblad BE, Høy K, Terkelsen CJ, Helleland HE, Terkelsen CJ. Handball injuries: An epidemiologic and socioeconomic study. The American Journal of Sports Medicine. 1992; 20(4):441-4. [DOI:10.1177/036354659202000413] [PMID]

[11] Strand T, Tvedte R, Engebretsen L, Tegnander A. [Anterior cruciate ligament injuries in handball playing. Mechanisms and incidence of injuries (Norwegian)]. Tidsskrift for den Norske Laegeforening: Tidsskrift for Praktisk Medicin, ny Raekke. 1990; 110(17):2222-5. [PMID]

[12] Wedderkopp N, Kaltoft M, Lundgaard B, Rosendahl M, Froberg K. Prevention of injuries in young female players in European team handball. A prospective intervention study. Scandinavian Journal of Medicine \& Science in Sports. 1999; 9(1):41-7. [DOI:10.1111/j.1600-0838.1999.tb00205.x] [PMID]

[13] Seil R, Rupp S, Tempelhof S, Kohn D. Sports injuries in team handball. The American Journal of Sports Medicine. 1998; 26(5):681-7. [DOI:10.1177/03635465980260051401] [PMID]

[14] Dirx M, Bouter LM, de Geus GH. Aetiology of handball injuries: A case-control study. British Journal of Sports Medicine. 1992; 26(3):121-4. [DOI:10.1136/bjsm.26.3.121] [PMID] [PMCID]

[15] Papacostas ET, Malliaropoulos N. Athletic injuries in team handball: A two-year study of a professional team. Medicine \& Science in Sports \& Exercise. 2001; 33(5):S185. [DOI:10.1097/00005768-200105001-01044]

[16] Petersen W, Braun C, Bock W, Schmidt K, Weimann A, Drescher W, et al. A controlled prospective case control study of a prevention training program in female team handball players: The German experience. Archives of Orthopaedic and Trauma Surgery. 2005; 125(9):614. [DOI:10.1007/s00402005-0793-7] [PMID]

[17] Reckling C, Zantop T, Petersen W. [Epidemiology of injuries in juvenile handball players (German)]. Sportverletzung Sportschaden. 2003; 17(3):112-7. [DOI:10.1055/s-2003-42149] [PMID]

[18] Lee Y, Nakagawa T, Miura T. [A study of sports injuries and behavior of handball players seeking medical advice after the injury I: Abut the injury situation Japanese and Korean teams (Japanese)]. Japanese Journal of Physical Fitness and Sports Medicine. 1998; 47(5):517-24. [DOI:10.7600/ jspfsm1949.47.517] 
[19] Myklebust G, Maehlum S, Engebretsen L, Strand T, Solheim E. Registration of cruciate ligament injuries in Norwegian top level team handball. A prospective study covering two seasons. Scandinavian Journal of Medicine \& Science in Sports. 1997; 7(5):289-92. [DOI:10.1111/j.1600-0838.1997. tb00155.x] [PMID]

[20] Asembo JM, Wekesa M. Injury pattern during team handball competition in east Africa. East African Medical Journal. 1998; 75(2):113-6. [PMID]

[21] van Mechelen W. Running injuries. Sports Medicine 1992; 14(5):320-35. [DOI:10.2165/00007256-199214050-00004] [PMID]

[22] Fuller CW, Ekstrand J, Junge A, Andersen TE, Bahr R, Dvorak J, et al. Consensus statement on injury definitions and data collection procedures in studies of football (soccer) injuries. Scandinavian Journal of Medicine \& Science in Sports. 2006; 16(2):83-92. [DOI:10.1111/j.1600-0838.2006.00528.x] [PMID]

[23] Hawkins RD, Fuller CW. A prospective epidemiological study of injuries in four English professional football clubs. British Journal of Sports Medicine. 1999; 33(3):196-203. [DOI:10.1136/bjsm.33.3.196] [PMID] [PMCID]

[24] Junge A, Dvorak J, Graf-Baumann T, Peterson L. Football injuries during FIFA tournaments and the Olympic Games, 1998-2001: Development and implementation of an injuryreporting system. The American Journal of Sports Medicine. 2004; 32(1_suppl):80-9. [DOI:10.1177/0363546503261245] [PMID]

[25] Junge A, Dvorak J. Influence of definition and data collection on the incidence of injuries in football. The American Journal of Sports Medicine. 2000; 28(5_suppl):40-6. [DOI:10.1177/28.suppl_5.s-40] [PMID]

[26] Visnapuu M, Jürimäe T. Relations of anthropometric parameters with scores on basic and specific motor tasks in young handball players. Perceptual and Motor Skills. 2009; 108(3):670-6. [DOI:10.2466/ pms.108.3.670-676] [PMID]

[27] Junge A, Rösch D, Peterson L, Graf-Baumann T, Dvorak J. Prevention of soccer injuries: A prospective intervention study in youth amateur players. The American Journal of Sports Medicine. 2002; 30(5):652-9. [DOI:10.1177/0363546502 0300050401] [PMID]

[28] Tsigilis N, Hatzimanouil D. Injuries in handball: Examination of the risk factors. European Journal of Sport Science. 2005; 5(3):137-42. [DOI:10.1080/17461390500221610]

[29] Andrén-Sandberg A, Lindstrand A. Injuries sustained in junior league handboll: A prospective study of validity in the registration of sports injuries. Scandinavian Journal of Social Medicine. 1982; 10(3):101-4. [DOI:10.1177/1403494882010003 06] [PMID]

[30] Hoeberigs J, van Galen WCC, Philipsen H. Pattern of injury in handball and comparison of injured versus noninjured handball players. International Journal of Sports Medicine. 1986; 7(06):333-7. [DOI:10.1055/s-2008-1025787] [PMID]

[31] Myklebust G, Engebretsen L, Brækken IH, Skjølberg A Olsen OE, Bahr R. Prevention of anterior cruciate ligament injuries in female team handball players: A prospective intervention study over three seasons. Clinical Journal of Sport Medicine. 2003; 13(2):71-8. [DOI:10.1097/00042752200303000-00002] [PMID]
[32] Rozzi SL, Lephart SM, Gear WS, Fu FH. Knee joint laxity and neuromuscular characteristics of male and female soccer and basketball players. The American Journal of Sports Medicine. 1999; 27(3):312-9. [DOI:10.1177/0363546599027003 0801] [PMID]

[33] Wekesa M, Njororai WWN, Madaga EL, Asembo JM. A comparative analysis of injuries in handball, hockey, volleyball and soccer in Kenya. African Journal of Health Sciences. 2001; 8(1-2):70-7. [PMID]

[34] Nielsen A, Yde J. An epidemiologic and traumatologic study of injuries in handball. International Journal of Sports Medicine. 1988; 9(05):341-4. [DOI:10.1055/s-2007-1025037] [PMID]

[35] Olsen O, Myklebust G, Engebretsen L, Holme I, Bahr R. Relationship between floor type and risk of ACL injury in team handball. Scandinavian Journal of Medicine \& Science in Sports. 2003; 13(5):299-304. [DOI:10.1034/j.16000838.2003.00329.x] [PMID]

[36] Vlak T, Pivalica D. Handball: The beauty or the beast. Croatian Medical Journal. 2004; 45(5):526-30. [PMID]

[37] Wedderkopp N, Kaltoft M, Lundgaard B, Rosendahl M, Froberg K. Injuries in young female players in European team handball. Scandinavian Journal of Medicine \& Science in Sports. 1997; 7(6):342-7. [DOI:10.1111/j.1600-0838.1997. tb00164.x] [PMID]

[38] Ohnjec K, Vuleta D, Milanović D, Gruić I. Performance indicators of teams at the 2003 world handball championship for women in Croatia. Kinesiology. 2008; 40(1):69-79. https:// hrcak.srce.hr/24835

[39] Liu SH, Al $\square$ Shaikh R, Panossian V, Yang RS, Nelson SD, Soleiman N, et al. Primary immunolocalization of estrogen and progesterone target cells in the human anterior cruciate ligament. Journal of Orthopaedic Research. 1996; 14(4):526-33. [DOI:10.1002/jor.1100140405] [PMID] 
This Page Intentionally Left Blank 